\title{
Cutaneous myeloid sarcoma associated with chronic myeloid leukemia*
}

\author{
Erica Rodrigues de Araujo Vasconcelos ${ }^{1}$ \\ Mayra Carrijo Rochael ${ }^{3}$
}

\author{
Alexander Richard Bauk²
}

DOI: http://dx.doi.org/10.1590/abd1806-4841.20176042

Abstract: Myeloid sarcoma is an extramedullary tumor of malignant myeloid cells often associated with acute myeloid leukemia, chronic myeloproliferative disorders and myelodysplastic syndromes. The skin is one of the most commonly affected sites. We report a rare case of cutaneous myeloid sarcoma associated with chronic myeloid leukemia.

Keywords: Immunohistochemistry; Leukemia, myeloid; Sarcoma, myeloid

\section{INTRODUCTION}

Myeloid sarcoma is a rare extramedullary tumor of malignant myeloid cells. It is also known as granulocytic sarcoma and chloroma, the latter due to a greenish color that is secondary to the enzymatic action of myeloperoxidase in the tumor cells. ${ }^{1,2}$ Since not all myeloid leukemias are derived from granulocytes and not all lesions show greenish color, the preferred term is myeloid sarcoma, instead of granulocytic sarcoma and chloroma.

Myeloid sarcoma may precede or occur concomitantly with acute and chronic myeloid leukemias, other myeloproliferative disorders, and myelodysplastic syndromes, or occur without known hematological disease. It is more common in adults between 45 and 55 years of age and the most affected sites are lymph nodes, skin, and bones (periosteum) ${ }^{1,3,4}$

We report a rare case of cutaneous myeloid sarcoma in a patient with chronic myeloid leukemia.

\section{CASE REPORT}

A 42-year-old African-descendant female patient reported painful and pruritic nodules on the trunk and limbs for two years and increased abdominal volume for three months. She denied fever. Physical examination showed violaceous nodules and tumors with some slightly greenish areas measuring 1 to $8 \mathrm{~cm}$ on the trunk and limbs (Figures 1 and 2). There was evidence of hepatomegaly and splenomegaly reaching the left iliac fossa. The complete blood count revealed hemoglobin of $10.3 \mathrm{~g} / \mathrm{dl}$, platelets of $150 \times 10^{3} / \mathrm{mm}^{3}$, and a white blood cell count of $282 \times 10^{3} / \mathrm{mm}^{3}$, with differentials of $52 \%$ segmented neutrophils, $9 \%$ band cells, $3 \%$ lymphocytes, $1 \%$ eosinophils, $1 \%$ monocytes, $4 \%$ basophils, $12 \%$ metamyelocytes, $8 \%$ myelocytes, $2 \%$ promyelocytes, and $8 \%$ blasts. Serologic tests for syphilis, HIV, and hepatitis B and C were negative. Bone marrow biopsy showed cellularity of $95 \%$ with predominance of granulocytes and their precursors, as well as megakaryocytic hyperplasia

\footnotetext{
Work submitted on 16.05.2016

Approved by the Advisory Board and accepted for publication on 29.09.2016

* Work performed at the Hospital Federal dos Servidores do Estado (HFSE-RJ), Rio de Janeiro RJ, Brazil.

Financial support: None

Conflict of interest: None

Dermatology Service, Policlínica Carlos Alberto Nascimento, Rio de Janeiro, RJ, Brazil.

Dermatology Service, Hospital Federal dos Servidores do Estado (HFSE-RJ), Rio de Janeiro, RJ, Brazil.

Department of Pathology, Universidade Federal Fluminense (UFF), Niterói RJ, Brazil.
} 
with hypo and hyperlobulated forms, compatible with chronic myeloproliferative disease. Cutaneous biopsy revealed normal-appearing epidermis, mild superficial and deep perivascular neutrophilic infiltrate in the dermis, and dense mixed infiltrate of neutrophils, lymphocytes, and medium-sized atypical round cells in the lobules and septa of adipose tissue, with surrounding megakaryocytes (Figure 3). The immunohistochemical study was positive for CD43, lysozyme, and myeloperoxidase, and proved to be negative for CD3, CD20, and CD30, confirming the diagnosis of myeloid sarcoma (Figures 4, 5 and 6). Treatment with imatinib mesylate at a dose of $600 \mathrm{mg}$ daily was begun, and the patient presented improvement of the cutaneous lesions, with her white blood cell count reaching normal values.

\section{DISCUSSION}

Chronic myeloid leukemia is a myeloproliferative disease that originates in an abnormal pluripotent bone marrow stem cell. It accounts for $15 \%$ to $20 \%$ of all cases of leukemia and can occur

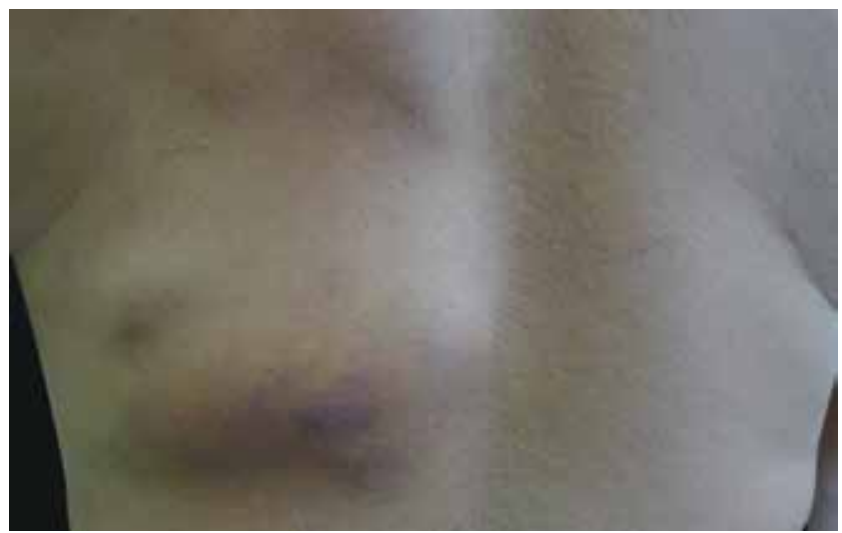

Figure 1: Violaceous tumor with greenish-colored nuances on the back

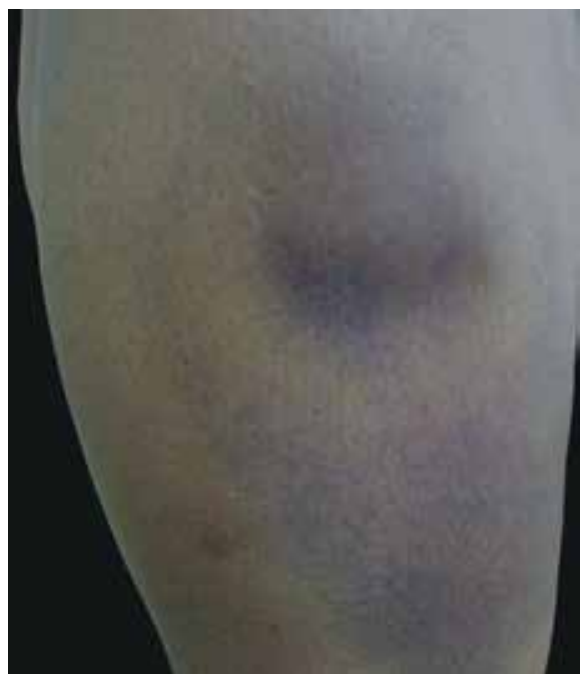

Figure 2: Violaceous tumor with greenishcolored nuances on the right upper limb at any age, but the average is between the fifth and sixth decades of life. ${ }^{5}$ It is characterized by the presence of the reciprocal translocation between chromosomes 9 and 22, resulting in the Philadelphia chromosome and the BCR/ABL fusion gene that encodes a protein with strong tyrosine kinase activity. ${ }^{6,7}$ In most cases, the diagnosis is based on blood count with leukocytosis and often thrombocytosis and differential revealing immature granulocytes, from metamyelocytes to myeloblasts. ${ }^{8}$ Bone marrow biopsy is hypercellular due to increased numbers of neutrophils and their precursors and the proliferation of megakaryocytes can also be observed. ${ }^{5}$

Myeloid sarcoma can occur in acute and chronic myeloproliferative disorders, with the potential for involvement of several organs, with cutaneous involvement accounting for $17 \%$ to $28 \%$ of the cases. Cutaneous myeloid sarcoma shows no gender predilection and is more common in acute myeloid leukemia, occurring in $2 \%$ to $3 \%$ of these patients. Rarely, it is associated with chronic myeloid leukemia. The lesions may appear as solitary or multiple violaceous, greenish, or skin-colored papules, nodules, plaques, or

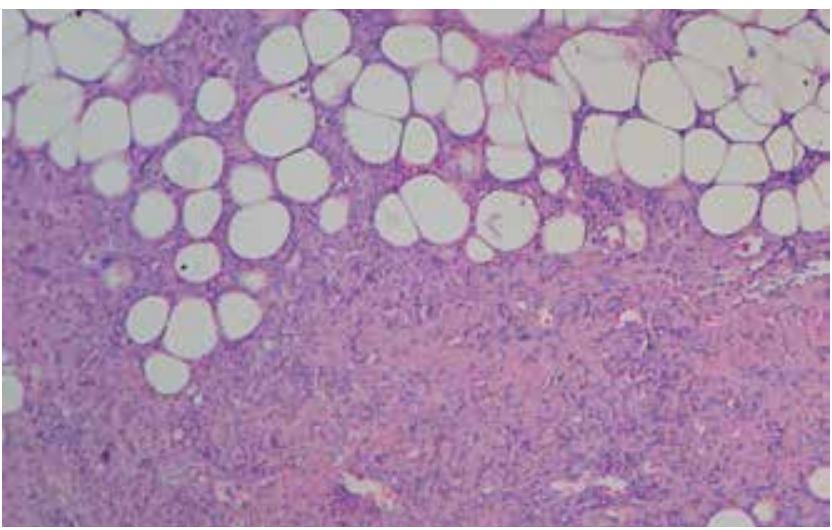

Figure 3: Histopathology: superficial and deep perivascular neutrophilic infiltrate in the dermis and dense mixed infiltrate of neutrophils, lymphocytes, and medium-size atypical round cells in the lobules and septa of adipose tissue (Hematoxylin \& eosin, X100)

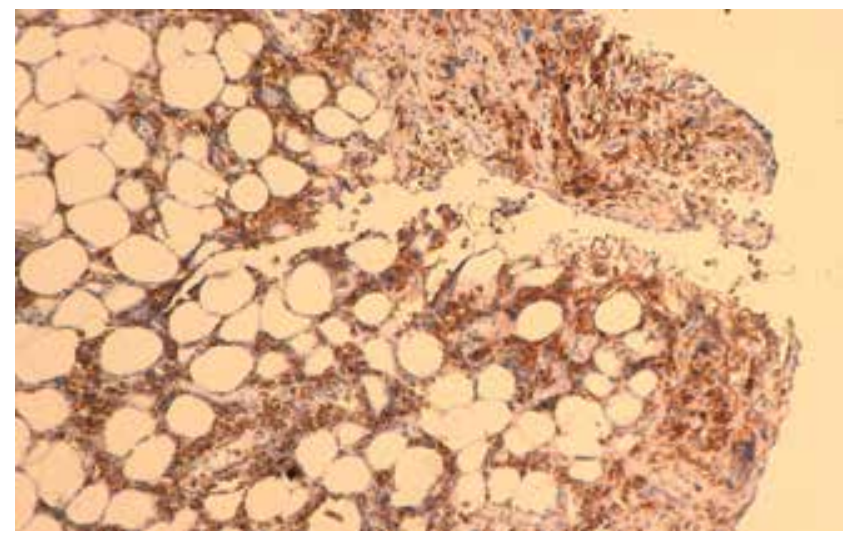

FIGURE 4: Immunohistochemistry positive for CD43 (X100) 


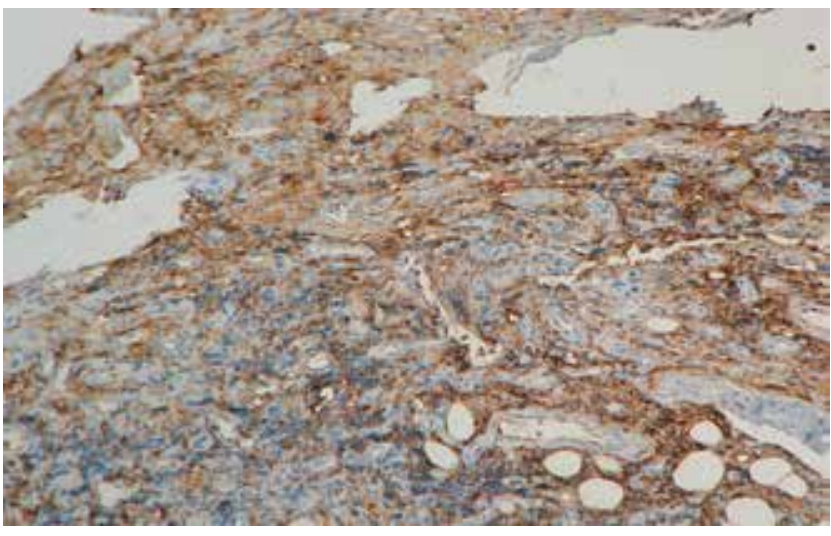

Figure 5: Immunohistochemistry positive for lysozyme (X100)

tumors, usually occurring on the trunk, scalp, and extremities. $4,7,9,10$ Histopathology reveals a generally spared epidermis and moderate or dense infiltrate in the dermis and subcutaneous tissue. In chronic myeloid leukemia, the infiltrate is more pleomorphic, with a predominance of mature and immature cells of the granulocytic series, and megakaryocytes may be present, as described in the case. ${ }^{3,9}$

The diagnosis of myeloid sarcoma is also based on immunohistochemistry. Myeloperoxidase and lysozyme are markers used to define the myeloid origin of the infiltrate. ${ }^{10}$ Neoplastic cells are negative for CD3, CD20, and CD30, most of which express CD45 and CD43. ${ }^{9}$ It is important to note that the CD43 marker may be positive in T-cell diseases. However, in the absence of CD3 reactivity, it suggests a myeloid tumor. ${ }^{4}$

\section{REFERENCES}

1. Diab M, Coloe J, Bechtel M. Extramedullary granulocytic sarcoma of the skin, mediastinum, and pericardium. Int J Dermatol. 2008;47:256-8.

2. Raja V, Bryant B, Bessman DJ, Alperin JB. Soft tissue sarcomas. Case 1. Granulocytic sarcoma: presentation with nodal and skin involvement. J Clin Oncol. 2004;22:2026-7.

3. Brunning RD, Matutes E, Flandrin G, Vardiman J, Bennett J, Head D et al. Acute myeloid leukaemia not otherwise categorised. In: Jaffe ES, Harris NL, Stein $\mathrm{H}$ Vardiman JW, editors. World Health Organization Classification of Tumours: Pathology and genetics of tumours of haematopoietic and lymphoid tissues. Lyon: IARC Press; 2001. p. 91-105

4. Câmara VMA, Morais JC, Portugal R, Carneiro SCS, Ramos-e-Silva M. Cutaneous granulocytic sarcoma in myelodysplastic syndrome. J Cutan Pathol. 2008:35:876-9.

5. Vardiman JW, Pierre R, Thiele J, Imbert M, Brunning RD, Flandrin G. Chronic myelogenous leukaemia. In: Jaffe ES, Harris NL, Stein H, Vardiman JW, editors World Health Organization Classification of Tumours: Pathology and genetics of tumours of haematopoietic and lymphoid tissues. Lyon: IARC Press; 2001. p. 20-6.

6. Almeida A, Castro I, Coutinho J, Guerra L, Marques H, Pereira AM. Recomendações para 0 diagnóstico, tratamento e monitorização da leucemia mielóide crónica. Acta Med Port. 2009:22:537-44.

7. Nagarajarao HS, Akhtar I, Heard K, Baliga M. Unusual presentation of chronic myelogenous leukemia as multiple skin chloromas: report of a case with clinical and cytologic correlation. Acta Cytol. 2009;53:235-8.

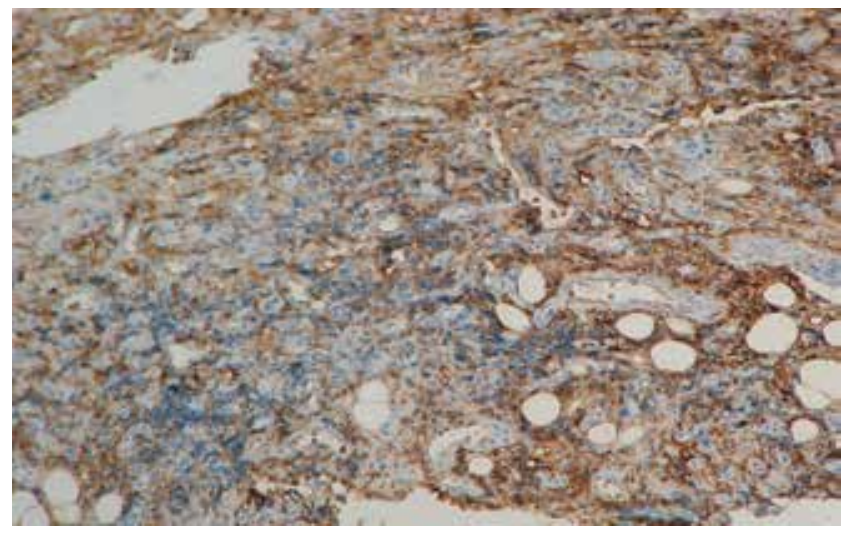

FIGURE 6: Immunohistochemistry positive for myeloperoxidase (X100)

Tyrosine kinase inhibitors are considered the first-line treatment in the vast majority of cases of chronic myeloid leukemia, thus justifying the use of imatinib mesylate. ${ }^{6}$

In this case report, the blood count and bone marrow biopsy findings are compatible with chronic myeloid leukemia, which was confirmed by the demonstration of BCR/ABL rearrangement in peripheral blood through the polymerase chain reaction (PCR). The diagnosis of leukemia in this case was made through the detection of myeloid sarcoma lesions - which were particularly exuberant making it possible for the dermatologist to eventually exercise the initial perception of the lymphoproliferative disease and promote a multidisciplinary approach. $\square$
MAILING ADDRESS:

Erica Rodrigues de Araujo Vasconcelos

Avenida das Américas 8585 sala 282

22793-296, Rio de Janeiro, RJ.

Brazil

E-mail:er.vasconcelos@uol.com.br

How to cite this article: Vasconcelos ERA, Bauk AR, Rochael MC. Cutaneous myeloid sarcoma associated with chronic myeloid leukemia. An Bras Dermatol. 2017;92(5 Suppl 1): 50-2. 